\title{
SEMIÓTICA DAS CULTURAS E CIÊNCIAS DA CULTURA SÉMIOTIQUE ET SCIENCES DE LA CULTURE
}

\author{
Nota epistemológica \\ Note épistémologique
}

Texto original em francês François RASTIER

INALCO-Fr

frastier@gmail.com

Tradução: Maria de Fátima B. De M. BATISTA

Universidade Federal da Paraíba-UFPB

mariadefatimambatista@gmail.com

\section{Introdução}

Desde muito tempo, a semiótica vem hesitando entre duas vocações: às vezes é definida como uma disciplina entre outras, às vezes como uma espécie de metadisciplina que teria a missão de redefinir dentro de si todas as ciências da cultura, mesmo uma parte boa das ciências naturais. Entre as duas, a imagem de uma "ciência piloto" se recuperou, devido à própria onipresença dos signos. Esta breve nota não tem outra ambição a não ser contribuir para o debate sobre o estatuto epistemológico da semiótica na sua relação com as ciências da cultura: não pode obviamente pretender expiá-las ou substituí-las, porque cada uma contém uma semiótica mais ou menos explícita e, muitas vezes, "em estado prático". Cabe à semiótica pensar nessas semióticas particulares para federá-las, ou pelo menos fortalecer sua federação.

\section{A renovação do saussurianismo}

A reflexão metodológica de Saussure favoreceu uma renovação epistemológica. Por um lado, é preciso um ponto de partida crítico para o desafio radical das crenças e preconceitos inquestionáveis que abundam na tradição gramatical. Isso supõe uma reflexão unificada que rejeita inconsistências e compromissos ecléticos. Por outro lado, sua metodologia exclui a metafísica ingênua da referência e todas as outras considerações externas à linguagem, para confiar na descrição das próprias linguagens, como visto, por exemplo, na teoria magistral da sílaba. Em outras palavras, Saussure parece tirar do seu objeto, as línguas, os próprios princípios de sua descrição: isso, no entanto, não é nem positivismo, nem empirismo indutivo, pois não procede por simples generalização, mas, através da teoria dos pontos de vista combinados em dualidades, modifica a própria noção de objetivação, o que pressupõe uma ruptura com a ontologia tradicional e permite poder chamá-la deontologia. 
O alcance de seu gesto teórico é imenso, já que interessa ao próprio status da teoria (como a linguística e as ciências da cultura seguiram as ciências da natureza, até mesmo as ciências lógico-formais). Muito tem sido filosofado sobre Saussure, a ponto de torná-lo uma espécie de filósofo da linguagem, sem absolutamente perceber que a filosofia da linguagem se torna uma filosofia das línguas, da forma como são objetivadas pela linguística e, portanto, uma filosofia da linguística.

No entanto, seu gesto teórico vai além das línguas para interessar a todos os sistemas de signos, de modo que o próprio projeto de semiótica deriva dele e se torna necessário. Esta não é uma definição de novos campos (todos os tipos de semiótica particulares já existem há muito tempo), mas a consideração de um ponto de vista unificado. É por isso que podemos considerar a semiótica, ora como uma disciplina, ora como um órganon ${ }^{1}$ para o conjunto de todas as ciências da cultura, sem que essas duas definições estejam em contradição.

Utilizando uma benigna ilusão retrospectiva, podemos ver, ainda, no projeto saussuriano, uma epistemologia programática, mas Saussure não tem nada de profeta e permanece portador de uma exigência radical, mais do que de um "programa" detalhado em boa e devida forma. Ele não planejou, nem chamou as várias correntes que reivindicam pertencer a ele, até o neo-saussurismo de nossos dias, e talvez tivesse sido severo para com eles. Não importa, depois de um século, a fecundidade de seus princípios dissidentes permanece intacta e mereceria ser melhor explorada.

Os "modelos semióticos" são, em primeiro lugar, na tradição Greimasiana, o "quadrado semiótico" e a estrutura narrativa básica universal? Os neogramáticos como, nos nossos dias, os gerativistas que os sucederam viram as "leis linguísticas" à imagem das leis físicas. É precisamente isso que Saussure rejeita.

Os modelos semióticos são concretizações lógicas, ou simplesmente figurativizações gráficas de tais leis fundamentais (nas quais, pudemos ver os princípios cognitivos, até mesmo morfologias matemáticas ainda mais gerais que justificariam uma "naturalização" da semiótica). Nessa hipótese, seria legítimo reencontrá-los, ou mesmo projetá-los em toda parte, já que leis dessa natureza devem seu refinamento à ubiquidade de suas verificações.

A questão permanece em aberto e defendo, favoravelmente, uma atitude prudente: as ciências da cultura são históricas e comparativas, podem tender à

\footnotetext{
${ }^{1}$ NT O conjunto dos escritos filosóficos de Aristóteles (384 a.C.-322 a.C.) que abordam o tema da lógica, considerada por seu autor um conhecimento cujo fim não está em si mesmo, sendo mais corretamente um meio, órgão ou instrumento para o pensamento correto e para a verdadeira ciência [A designação, entretanto, foi dada pelos comentadores gregos do corpus aristotélico].
} 
generalidade sem erigir, as universais, as regularidades que objetivam. Não podemos concluir do geral para o universal, especialmente porque as culturas são desigualmente documentadas e o etnocentrismo não desapareceu.

Para definir a semiologia, faz-se referência, em primeiro lugar, ao parágrafo do Curso de Linguística Geral que, a ele, é dedicado. No entanto, se considerarmos as fontes autógrafas e as anotações estudantis, vemos que os editores do Curso retiveram e, de fato, impuseram uma concepção limitada da semiótica que a torna uma ciência dos sistemas de signos, que permanece compatível com a concepção gramatical da linguagem como um sistema. Essa concepção prevaleceu em grande parte e as introduções à semiologia enumeram esses sistemas (jogos, uniformes, sinais de trânsito, etc.).

Tal concepção aditiva da semiologia lembra fortemente o Tractatus de signis e outros tratados que se sucederam ao longo dos séculos até Peirce. No entanto, a ambição da linguística histórica e comparada vai além da descrição dos sistemas gramaticais, porque contribui para o projeto de uma antropologia geral da qual Humboldt delineou os contornos.

Ora, refletindo sobre a relação entre os dois polos da dualidade entre o social e o individual, Saussure enfatiza que todos os sistemas de signos são instituições: a língua é uma delas, aliás, única em seu gênero, a escrita é outra, etc. Como a dimensão social predomina em última instância, os diferentes sistemas de signos só podem ser compreendidos em relação às sociedades que os estabelecem. É, portanto, ao projeto de uma antropologia - não mais filosófica, mas histórica e comparativa - que se deve relacionar a semiologia . Ela deriva do programa humboldtiano que Saussure radicaliza e concorda com as ideias daquele autor que confidenciou que apenas o aspecto etnográfico das línguas tinha algum interesse para ele. Assim, ele denunciava, obliquamente, a problemática dos neogramáticos que se atinham a um estudo "interno" das línguas , prefigurando assim os chomskanianos de hoje.

Referindo-se à própria estrutura do signo como objeto cultural, a dualidade entre as duas concepções, a restrita e a ampliada, da semiótica se reflete na cisão entre o conteúdo e o alcance do signo. Como o significado do signo está sob o controle do significado textual, seu conteúdo só pode ser completamente determinado por seu escopo. Ao mesmo tempo, a semiologia como descrição dos sistemas de signos depende da descrição das instituições sociais que os constituem. Além disso, eles não os refletem porque fazem parte disso. 


\section{A questão da interdisciplinaridade.}

A invocação repetida da interdisciplinaridade pode parecer encantadora, se apenas traduz, trai e ilusoriamente compensa a fragmentação das disciplinas conduzidas em nome de uma hiper-especialização acrítica. A interdisciplinaridade continua sendo uma noção problemática, até mesmo um simples slogan, desde que permaneçam com generalidades desinformadas, sem distinguir, para cada disciplina, seu objetivo, a especificidade de seu objeto, seu objetivo enfim. Por outro lado, em certos círculos das humanidades influenciadas pela filosofia desconstrutivista, a própria noção de disciplina é apagada em face de um discurso, repugnante à objetivação, cujas dimensões atestam que nenhum critério permite que ela seja concluída. A própria noção de disciplina parece então ser disciplinar, no sentido repressivo do termo.

A interdisciplinaridade permanece um desejo, desde que não se encontre uma linguagem ou procedimentos comuns de "tradução" entre disciplinas. Para o estruturalismo, foram a filosofia e a magistral reconstrução filosófica das ciências por Cassirer e Simondon, redobradas pelas reflexões filosóficas de cientistas como LéviStrauss (aliás, um "desertor" da filosofia à qual estava engajado desde o início), ou LeroiGourhan. É por isso que a desconstrução, ao longo dos anos, vem trabalhando para arruinar a língua comum da filosofia da ciência por um discurso aporético que se tornou anedótico, mas em grande parte dominante, em algumas áreas das ciências humanas. Quarenta anos após o de Heidegger contra Cassirer, o ataque de Derrida contra Saussure foi resumido a um julgamento falso, baseado em um texto amplamente apócrifo, mas que tinha um significado simbólico: dissociar as ciências da cultura do "pensamento" de Heidegger e perpetuava sua rejeição ao princípio de toda a ciência e impossibilitava sua autorreflexão na filosofia.

Outra linguagem comum era a da "filosofia formal", de acordo com a expressão do editor de Montague. 0 grande fluxo de logística de Russell, ao qual Whitehead deu uma interpretação amplamente platônica, lembrou o parentesco milenar da filosofia e da matemática. No início dos anos 1930, o programa de formalização experimentou uma inflexão materialista com o Círculo de Viena. O projeto de unificação das ciências, formulado mais tarde por Morris e Carnap na Enciclopédia de Ciências Unificadas, distingue-se, ao mesmo tempo, pela ambição de unificar todas as ciências por critérios cientificistas que excluíam, de fato, o essencial das ciências da cultura.

Popper então formulou critérios de cientificidade que são perfeitamente adequados às ciências experimentais, mas dificilmente à maioria das ciências da cultura; 
quando eles são aplicados, como têm sido por influentes formadores de decisão, eles as levam à marginalização.

A imagem da ciência transmitida por esses critérios foi chamada de "galiliana" por Milner em seu elogio a Chomsky; sua Introdução à ciência da linguagem vincula o início da linguística ao projeto de Chomsky e mantém em silêncio o século e meio que o precedeu. Essa concepção da ciência baseia-se na imagem da física newtoniana: o princípio da causalidade leva à enunciação das leis. Ela é, se não caduca, pelo menos desatualizado pela física, matemática (incluindo a geometria não euclidiana) desde a virada dos anos 1880-1920. Nas ciências da cultura, as causas provocam rendimento às condições e, especialmente, às correlações de condições; a declaração de leis para as conjecturas do raciocínio probabilístico; por fim, as regularidades não são mais absolutas, mas deixam espaço para acontecimentos singulares.

0 consenso sobre o que é uma teoria condiciona dois tipos de interdisciplinaridade.

(i) A primeira, despercebida, é a interdisciplinaridade interna: por causa da crescente disciplinarização que, por exemplo, leva a considerar que a linguística dá lugar às ciências da linguagem, ou que a morfologia é uma disciplina diferente de sintaxe; é importante reafirmar a unidade (muito conquistada) dos campos disciplinares. Saussure formulou, magistralmente, o todo ser inseparável).

(ii) A interdisciplinaridade "externa" continua sendo uma palavra-chave para os tomadores de decisão. Paradoxalmente, funciona melhor entre departamentos científicos do que dentro do mesmo departamento: um arqueólogo colabora, sem escrúpulos, com um palinologista, mas, dentro das ciências sociais, brigas de fronteira existem (acadêmicas e às vezes científicas).

Não vamos postular uma unidade supra teórica, mas esperar uma vontade comum para reconhecer a complexidade dos fatos culturais e um projeto comum de objetificação. Elas se encontram pelos problemas, falam sobre objetos e permanecem unidas pelo conceito de verdade científica que une a as ciências: seus princípios são compartilhados, embora cada um difira por seus métodos e fórmulas de validação.

O diálogo entre teorias (parciais) no mesmo domínio ou entre domínios (isoladamente na literatura comparada) só é possível se não desistirmos do projeto de conhecimento para um projeto de "intervenção crítica": o status de teorias "críticas" são problemáticas. Um resultado científico resulta de uma atividade crítica, necessária à deontologia científica. Uma vez estabelecido, não é crítico por si só, mas, mesmo assim, exerce uma crítica aos preconceitos que dissipa.

\section{Lógica, morfologia e organon semiótico.}


Em alguns aspectos, a lógica pode ser usada pelas ciências da cultura; por exemplo, ela tem sido usada em linguística no estudo da argumentação. Pode-se até argumentar que a lógica é uma parte muito restrita da semiótica.

Não está a semiótica, agora, numa situação comparável à da lógica no passado, tanto como disciplina, quanto como organon para outras disciplinas? Locke como Peirce e muitos outros identificaram a lógica e a semiótica. Essa assimilação é baseada na ideia clássica de que o pensamento é constituído de operações sobre sinais mentais que são encontrados nos Senhores de Port-Royal em Condillac e até Destutt de Tracy. A relação entre os sinais mentais e os signos linguísticos vai preocupar as gramáticas gerais dos séculos XVII e XVIII, até as gramáticas cognitivas de hoje - daí o interesse de Chomsky pela linguística cartesiana.

A linguística histórica e comparada, contudo, dificultou a relação especulativa entre sinais mentais universais e determinados signos linguísticos, variáveis e contingentes, simplesmente porque repatria o significado nas línguas e delega "conteúdos mentais" a outras disciplinas, da lógica à psicologia. 0 problema da relação entre expressões empíricas e conteúdos transcendentes está desatualizado, juntamente com o dualismo tradicional que se opõe à matéria e ao espírito.

Ele é desafiado pela dualidade específica da semiose, definida como o pareamento de conteúdos e expressões: no nível do texto, caracteriza a textualidade; semiótica, entendida como um emparelhamento de uma forma do conteúdo e uma forma de expressão. No momento desta tomada temporária de forma, o signo se individualiza, torna-se uma ocorrência única, um hápax². As ocorrências mais próximas e mais repetitivas constituem um repertório de expressões e conteúdos estereotipados (fraseologias e doxa).

Ora a lógica clássica operava com signos mentais já discretizados e constituídos em repertório, assim como a gramática para os signos linguísticos, o que permitia acasalamentos termo a termo, tanto na lógica, quanto na gramática. Por outro lado, como mostra o estudo dos textos, a linguística lida com formas que escapam à lógica por

\footnotetext{
2 NT Um hápax ou hápax legómenon é uma palavra que aparece registrada somente uma vez em um dado idioma. Braquilogia (cfr Braquigrafia) de hápax legómenon (ámáł $\lambda \varepsilon \gamma o ́ \mu \varepsilon v o v$ ) ou hápax eirémenon


diz", "o dito"]. Esta expressão designa uma palavra que se utilizou ou registrou apenas uma vez num corpus. Também se pode entender como um vocábulo do qual só se tem um exemplo numa época dada, num autor ou na totalidade de uma obra. Até onde se sabe, esta expressão aparece registrada pela primeira vez num texto inglês de 1654 (John Trapp: Annotations upon the Old and New Testament, IV, 605, NED Suppl.).
} 
seu caráter contínuo e por suas constantes transformações, exigindo uma morfologia, ou mesmo uma morfológica.

A reflexão morfológica está presente desde os primórdios da linguística, notadamente em Humboldt, inspirados pelas reflexões de Goethe e sua importância será lembrada por Cassirer em seu último artigo Estruturalismo na moderna Linguística. Além disso, o "quadrado semiótico" (segundo Greimas e Rastier, 1968) concretizava a ideia geral de que estava faltando uma teoria não lógica das operações de constituição e evolução das formas semióticas. Se ele chamava desenvolvimentos morfológicos (não lógicos) que têm sido lentos devido à predominância de problemas lógico-gramaticais, infelizmente, ele foi considerado um modelo (em todos os sentidos) e acabou sendo iconizado por um caminho acrítico.

Impõe-se a necessidade de uma reconcepção morfológica do conceito de estrutura. Foi antecipado por uma morfossemiótica como a de Pottier, elaborada desde o início da década de 1960, notadamente em seu modelo de preposições latinas e até sua Ilustrada Semântica (2018); e, claro, as importantes contribuições de Petitot na Morfogênese do significado (1985). A morfossemiótica oferece novas respostas para o duplo problema da transponibilidade das estruturas e seus regimes evolutivos, notadamente pela mobilização da teoria dos sistemas dinâmicos (ver o autor, 1999c e David Piotrowski, Morfogênese do signo, Berlim, Springer, 2017, segunda edição aumentada).

Em suma, os modelos lógicos representam apenas uma parte muito pequena dos modelos matemáticos, mais poderosos e diversificados. Ao determinarem o discreto como um "caso especial" do continuum, tornam possível colocar o problema, que é simultaneamente perceptivo e cognitivo, da discretização. A teoria dos grupos, a teoria dos sistemas dinâmicos, a topologia, a teoria das catástrofes têm sido usadas de maneira variada para lidar com problemas de morfologia semiótica. A linguística de corpus também tem explorado modelos probabilísticos para identificar formas, tanto por correlações internas entre seus pontos singulares, privilegiadas pelo estruturalismo "clássico", quanto pelos segmentos de contorno, favorecidos pela abordagem morfológica. Complementarmente, busca caracterizar as formas por seus contrastes recíprocos.

Esses modelos escapam pelo princípio ou tudo ou nada e retêm proximidades ou distâncias. Além disso, é a necessidade de uma semiótica do corpus que se impõem, no presente, como necessária, não apenas para a crítica dos "dados", mas para a instrumentação racional da pesquisa². 


\section{Ajuda mútua entre ciências}

Como disciplina, a semiótica tem seu lugar entre as ciências da cultura, especialmente para diversificar e comparar diferentes "formas simbólicas" ou instituições semióticas, como mito, arte, direito ou linguagem.

Como órganon, a semiótica pode propor conceituações e, até mesmo, tipos de formalizações que cada disciplina pode apreender de modo a torná-las operativas em seu seio para seus próprios problemas.

No entanto, a situação da semiótica não lhe confere um status excepcional: todas as disciplinas participam de círculos auxiliares, onde cada um pode assumir um papel auxiliar em relação aos outros, enquanto ajuda em troca de sua colaboração. Por exemplo, a lógica e, mais genericamente, a matemática pode guiar a semiótica na elaboração de seus modelos e em sua instrumentação, como evidenciado pelo software de interrogação e exploração em linguística de corpus, como em iconologia ou musicologia.

Da mesma forma, as ciências da cultura, como a arqueologia, a história, a etnografia, cooperam com as disciplinas das ciências da vida, como a palinologia e trazem proveito, pelas suas datações, na restauração de contextos desaparecidos, técnicas como espectrografia, etc.

Lembremos, finalmente, que a semiótica também se estende às ciências da vida, como o evidencia a ascensão dos zoossemióticos; no entanto, exigiria um desenvolvimento que ultrapasse o escopo desta nota.

\section{Referências}

NB: Como alguns desses pontos exigiriam uma bibliografia excessiva, para uma simples nota, vou me limitar a referir algumas publicações anteriores que prefiguram ou apoiam minhas observações.

1999a: «Representation or interpretation?», Linguistics in the Morning Calm, 4, Séoul, The linguistic society of Korea, pp. 115-135.

1999b: «La sémiotique: fondations et fondements - Remarques épistémologiques», in Mélanges de linguistique, sémiotique et narratologie dédiés à Krassimir Mantchev, Editions Colibri, Sofia, pp. 337-352.

1999c: «Cognitive Semantics and Diachrony», in Andreas Blank et Peter Koch, éds., Historical Semantics and Cognition, Mouton de Gruyter, Berlin (Cognitive Linguistics Research), pp. 109-144.

1999d: «Sign and Symbol: Semiotics and Cognitive Science», in H.S. Gill, et G. Manetti, éds. Signs and Signification, II, Bahri Publications, New Delhi, pp. 199-208.

2001a: «L'action et le sens. — Pour une sémiotique des cultures, » Journal des Anthropologues, 85-86, pp. 183-219.

2001b «Sémiotique et sciences de la culture, » Linx, 44-45, pp. 149-168. Réédition: Acta semiotica et linguistica, 33, 1, 2009, pp. 35-64.

2002: «Anthropologie linguistique et sémiotique des cultures, in S. Bouquet et F. Rastier, éd., Une introduction aux sciences de la culture, Paris, PUF, ch. 14, pp. 243-267. 
2004a: «Sciences de la culture et post-humanité», Actes 2003/2004 du groupe de travail STP (du Sujet : Théorie et Praxis) de la Maison des Sciences de l'Homme de Paris. Volume 7. Editions MSH Paris, pp. 7-27.

2009: «La sémiotique des cultures», in Driss Ablali et Dominique Ducard, Vocabulaire des études sémiotiques et sémiologiques, Paris, Champion, 2009, pp. 89-95 [avec la collaboration de Carine DuteilMougel].

2004b: «Naturalisation et culturalisation,» in L'évolution aujourd'hui: à la croisée de la biologie et des sciences humaines, Bruxelles, Académie Royale de Belgique, pp. 231-250.

2010: Ação e sentido - por uma semiótica das culturas, Editora Universitária da UFPB, João Pessoa-PB. Traduction de L'action et le sens pour une sémiotique des cultures par Maria de Fátima Barbosa de Mesquita Batista.

2011a: «Sémiotique et linguistique de corpus, Signata, I, 1, pp. 9-34.

2011 « «Objets culturels et performances sémiotiques —L'objectivation critique dans les sciences de la culture», in Louis Hébert et Lucie Guillemette Performances et objets culturels, Québec, PU Laval, pp. 15-58.

2014a: «La formation de la sémiotique saussurienne et l'historicité spécifique des sciences de la culture», in Wulf Oesterreicher et Maria Selig (Hg.) Geschichtlichkeit von Sprache und Text Philologien Disziplingenese - Wissenschaftshistoriographie, Munich, Fink, pp. 213-230.

2014 b «Sciences de la culture et cosmopolitisme», in 60 Years of Foreign Studies, actes de The international conference for celebrating the 60th anniversary of the foundation of Hankuk University of Foreign Studies, Séoul, pp. 85-102.

2015: Semiótica e Cultura: dos discursos aos universos construídos, Congresso Internacional de Semiótica e Cultura - Semicult, Joao Pessoa, Editora da UFPB, 538 p. Direction de l'ouvrage, en collaboration avec Maria de Fatima Barbosa de M. Batista.

2017: «De la sémantique structurale à la sémiotique des cultures», Actes sémiotiques, n²120, 24 p. en ligne: http://epublications.unilim.fr/revues/as/pdf/5734.

2018: "Computer-Assisted Interpretation of Semiotic Corpora», in Dario Compagno, éd., Quantitative Semiotic Analysis, Lecture Notes in Morphogenesis book series, Berlin, Springer, pp. 123-139.

— «Cassirer et la création du structuralisme», Acta Structuralica, avril 2018, n spécial 1, pp. 29-51. Aussi en ligne: http://acta.structuralica.org/2018/04/01/cassirer-et-la-creation-du-structuralisme/. 